\title{
Impact of drainage technique on pediatric pyeloplasty: Comparative analysis of externalized uretero-pyelostomy versus double-J internal stents
}

\author{
Linda C. Lee, MD, FRCSC; Niki Kanaroglou, MD, FRCSC; Joseph M. Gleason, MD; Joao L. Pippi Salle, MD, \\ FRCSC; Darius J. Bägli, MD, FRCSC; Martin A. Koyle, MD, FAAP, FACS, FRCS (Engl.), FRCSC; \\ Armando J. Lorenzo, MD, MSc, FRCSC, FAAP, FACS
}

Division of Urology, Hospital for Sick Children and Department of Surgery, University of Toronto, Toronto, ON

Cite as: Can Urol Assoc J 2015;9(7-8):E453-7. http://dx.doi.org/10.5489/cuaj.2697

Published online July 17, 2015.

\section{Abstract}

Introduction: Pediatric pyeloplasty with double J (DJ) stent drainage requires manipulation of the uretero-vesical junction (UVJ) and a second anesthetic for removal. Externalized uretero-pyelostomy (EUP) stents avoid these issues. We report outcomes of laparoscopic and open pyeloplasty with EUP compared to DJ stents in children. Methods: We retrospectively reviewed 76 consecutive children who underwent pyeloplasty for ureteropelvic junction (UPJ) obstruction over a 1-year period by 5 pediatric urologists at a single institution. The exclusion criteria included patients with concomitant urological procedures, other urinary drainage strategies, "stentless" pyeloplasty or patients without follow-up data. Based on surgeon preference, 24 patients had a EUP stent and 38 had a DJ stent placed.

Results: The mean follow-up was $23.8 \pm 10.9$ months and $21.1 \pm 11.1$ months for the EUP and DJ stent groups, respectively $(p=0.32)$. The mean age was $40 \pm 54$ months and $80 \pm 78$ months for the EUP and DJ groups, respectively $(p=0.04)$. The EUP group had a greater proportion of open pyeloplasties $(n=17,71 \%)$ versus the DJ group $(\mathrm{n}=16,42 \% ; p=0.04)$. There were no statistically significant differences in operative time, length of stay, and overall complication rate between groups. Complications were divided by timing of complication (intraoperative, before and after 3 months) and according to the Clavien Classification system. There were no statistically significant differences between these subgroups. The limitations of this study include small sample size, potential selection bias, and heterogeneity between both study groups.

Conclusions: Pyeloplasty using EUP stents does not incur prolonged operative time, longer length of stay or higher complication rate when compared to DJ stents. Within the limitations of this study, EUP stents may be a safe alternative to DJ stents.

\section{Introduction}

The role of trans-anastomotic drainage after pyeloplasty in children remains controversial. While "stentless" pyeloplasty has gained popularity over the years, ${ }^{1,2}$ concerns regarding prolonged urinary leak, risk of impaired postoperative antegrade flow due to edema, and need for a secondary procedures have supported the use of stent drainage following pyeloplasty. ${ }^{3}$ Options for trans-anastomotic catheters include internal double J (DJ) and externalized stents. ${ }^{4,5}$ While DJ stents remain popular, disadvantages include lower urinary tract symptoms, difficulty negotiating the wire or stent across the uretero-vesical junction (UVJ), and deployment in the distal ureter when place $d$ in an antegrade fashion. In most cases, placement requires a second anesthetic for removal in children. There is evidence that anesthetic exposure may be associated with neurotoxicity in young children ${ }^{6}$ and an ongoing prospective trial will examine these risks. ${ }^{7}$ In particular, externalized trans-anastomotic stents can avoid many of the disadvantages of DJ stents. The distal end of an EUP stent may be tailored so that it reaches the mid-ureter, avoiding UVJ trauma and lower urinary tract symptoms. EUP stents can also be removed in the ambulatory setting without sedation. The catheter may be opened to straight drainage if a urine leak develops and access allows for a postoperative nephrostogram, if indicated.

Externalized stents can exit the kidney through the renal parenchyma or the renal pelvis. The kidney internal splint/ stent (KISS) stent (Cook Urological, Spencer, IN) ${ }_{1}^{8}$ externalized feeding tubes and the Salle intraoperative pyeloplasty stents $^{9}$ (Cook Urological, Spencer, IN) have been traditionally passed through the renal parenchyma. Recently, advancing the stent through the renal pelvis has been reported as a technically easier option that avoids the risk of bleeding. This technique has been reported for open, laparoscopic 
retroperitoneal, and laparoscopic trans-peritoneal pyeloplasties, and appears safe and feasible. ${ }^{10-12}$

Literature directly comparing drainage with trans-anastomotic stents externalized through the renal pelvis versus DJ stents in children undergoing both laparoscopic and open pyeloplasties is limited. We sought to compare outcomes of both open and laparoscopic pyeloplasty using EUP and DJ stents.

\section{Methods}

We evaluated 76 consecutive patients who underwent surgery for ureteropelvic junction obstruction (UPJO) by 5 pediatric urologists at a single institution between 2011 and 2012. Diagnosis was confirmed based on renal ultrasound and diuretic nuclear renography. The exclusion criteria included ureterocalicostomy $(n=2)$, simultaneous major surgery $(n=1)$, drainage using an open-ended ureteral catheter $(n=1)$, "stentless" pyeloplasty $(n=4)$, and patients who were lost to follow-up $(n=6)$. The remaining 62 patients underwent an Anderson-Hynes dismembered pyeloplasty with drainage using a EUP stent or DJ stent, via an open or laparoscopic approach, based on surgeon preference. The EUP stent used at our institution is the Salle intraoperative pyeloplasty stent (Cook Urological, Spencer, IN).

Employed surgical techniques have been previously reported, ${ }^{12}$ with minor modifications. An abdominal radiograph depicting bilateral EUP stents in situ is shown is Figure 1. Intra-operatively, the distal coil of the EUP stents was removed (Fig. 2a). For open cases, a 12-gauge angiocatheter was used to facilitate placement of the EUP stent through the skin and the renal pelvis (Fig. 2b), after the initial anastomotic sutures were placed at the apex. To avoid unraveling the coil in the pelvis and to optimize drainage, we used a small absorbable suture to keep the loop together (Fig. 2a).

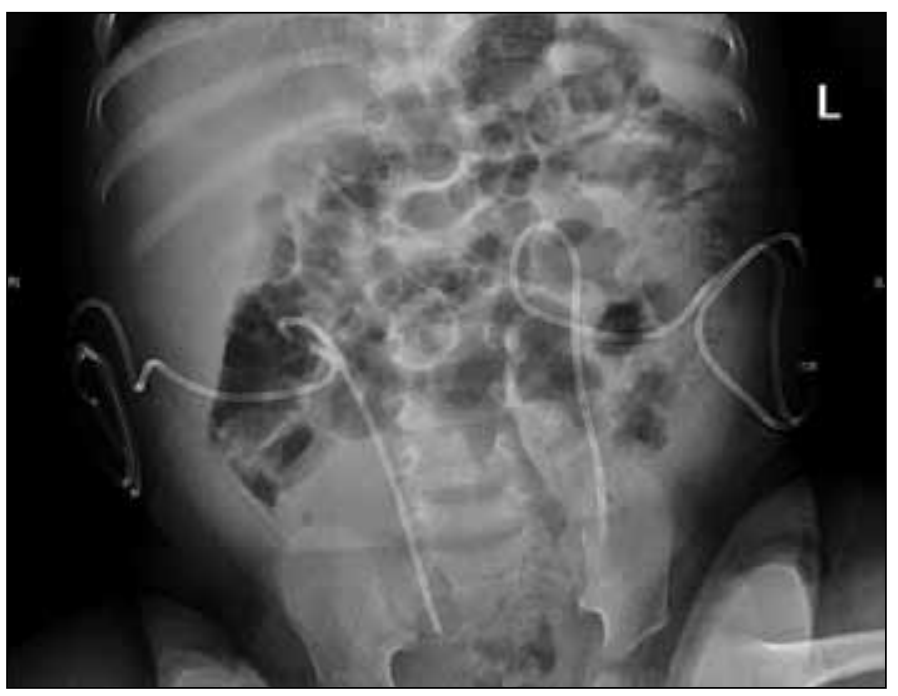

Fig. 1. Kidney-ureter-bladder X-ray of a patient with bilateral externalized uretero-pyelostomy stents.
A purse-string suture was placed intra-operatively at the stent exit site out of the renal pelvis to prevent urine leak. The laparoscopic approach has been previously described. ${ }^{12}$ EUP stents were clamped at the end of the surgery (Fig. 2c), and indwelling Foley catheters were removed right after surgery or during the first 12 hours (according to surgeon preference). All patients had a follow-up renal ultrasound at 3 months and serial ultrasounds thereafter. The timing of serial ultrasounds after the 3-month mark was based on surgeon preference. Only children with lack of improvement in hydronephrosis underwent diuretic nuclear renography. ${ }^{13}$ We assessed the primary outcome, intra- and postoperative complications (subdivided by timing before and after 3 months), and severity of complication according to the Clavien-Dindo Classification system. ${ }^{14}$

Ethics approval for this study was obtained by our institutional Research Ethics Board. Continuous variables were examined using a two-sided student's t-test and categorical variables were examined using Fisher's exact test. Statistical analyses were performed using Prism 6 (GraphPad, San Diego, CA). A $p$ value cut-off of 0.05 was considered statistically significant.

\section{Results}

Of the 62 consecutive patients in our series who underwent Anderson-Hynes dismembered pyeloplasty, 38.7\% $(\mathrm{n}=24)$ had an EUP stent and $62.3 \%(\mathrm{n}=38)$ had a DJ stent placed intra-operatively (Table 1 ). Patients who had EUP stents tended to be younger, with a mean age of 40 months \pm 54 months, presenting with antenatal hydronephrosis $(79 \%, n=19)$. In contrast, patients who had a DJ stent

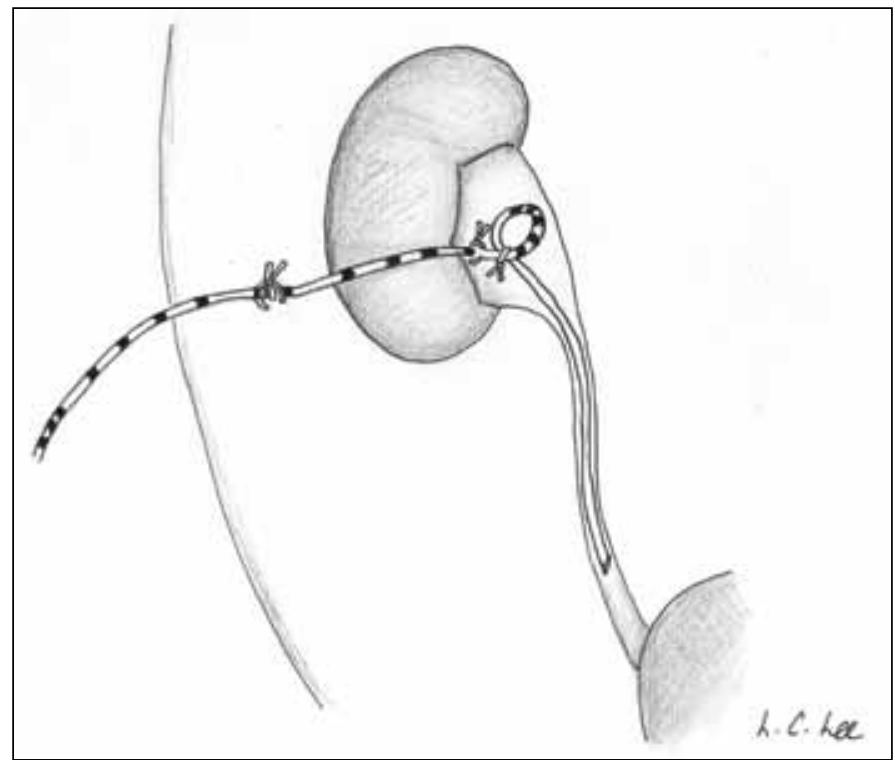

Fig. 2a. Angiocatheter used to facilitate passage of an externalized ureteropyelostomy stent during an open pyeloplasty. 


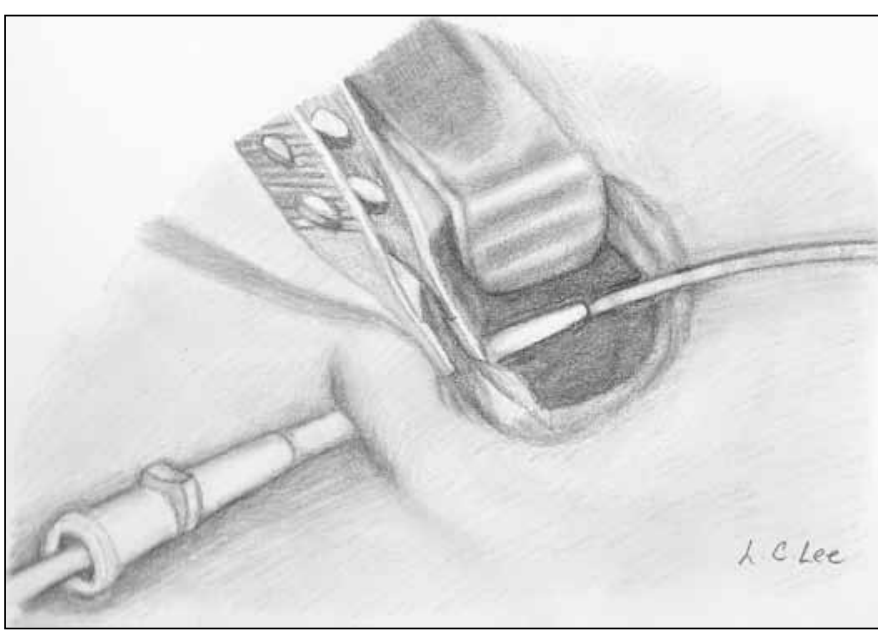

Fig. 2b. Retention loop of the externalized uretero-pyelostomy stent reinforced with a dissolvable 4-0 chromic stitch.

tended to be older, with a mean age of $80 \pm 78$ months and presented with antenatal hydronephrosis and symptomatic UPJO in $45 \%(n=17)$ and $32 \%(n=12)$, respectively. Disparities in approach (laparoscopic vs. open) were close to the cut-off value for statistical significance $(p=0.04)$.

The outcomes and complications are summarized in Table 2. None of the patients in the EUP group had a perinephric drain placed, while all children with a DJ stent had one that was removed prior to discharge except for one case of prolonged urinary leak. In this patient, expectant management with an intra-peritoneal Jackson-Pratt drain placed at the time of surgery led to a prolonged stay in hospital ( 6 days), but resolution of urine leak. In addition one patient in the DJ group had an accidental removal of the stent during Foley catheter removal on postoperative day 1 . No complications occurred as a result of this.

The mean follow-up was 23.8 and 21.1 months for the EUP group and DJ groups, respectively $(p=0.32)$. Treatment success was defined as improvement in symptoms or improved hydronephrosis. In the EUP group, one patient had recurrent symptoms, despite improved hydronephrosis and a normal Lasix renogram, and was monitored conservatively. Another two patients in the EUP had worsening hydronephrosis, which improved following cystoscopy, ureteral dilation, and stenting. In the DJ group, one patient had recurrent pain, stones and hydronephrosis, who improved with ureterocalicostomy. Another two patients in the DJ stent group had worsening hydronephrosis, including one case where renal function declined postoperatively from $40 \%$ to $10 \%$. We performed a dimercaptosuccinic acid (DMSA) scan in another patient, confirming good function (64\%) and we therefore watched the patient conservatively.

Complications were examined according to the ClavienDindo classification. ${ }^{14}$ Clavien I complication (e.g., postoperative fever secondary to atelectasis) occurred in $4.2 \%$

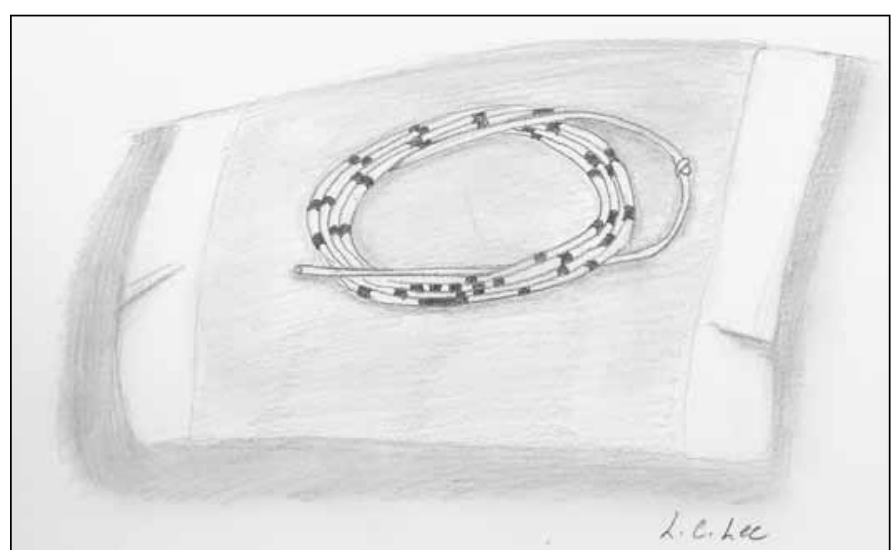

Fig. 2c. An externalized uretero-pyelostomy stent is tied off distally and coiled under a large tegaderm dressing.

$(\mathrm{n}=1)$ and $2.6 \%(\mathrm{n}=1)$ in the EUP stent and the DJ groups, respectively $(p=0.01)$. Clavien II complications occurred in $8.3 \%(\mathrm{n}=2)$ and $0 \%$ in the EUP stent and DJ groups, respectively $(p=0.15)$. These two patients in the EUP stent group were readmitted for abdominal pain, nausea, and vomiting and immediate imaging did not show increased hydronephrosis. These symptoms were attributed to side effects of narcotics and managed with antiemetics and laxatives. These patients responded well and were subsequently discharged from hospital. Many of the aforementioned complications are unlikely to be related to the method of stenting.

Clavien III complications occurred in $8.3 \%(n=2)$ and $2.6 \%(n=1)$ in the EUP and DJ groups, respectively, although the differences were not statistically significant $(p=0.55)$. These included 2 patients in the EUP stent group who had

Table 1. Patient demographics

\begin{tabular}{|c|c|c|c|}
\hline & $\begin{array}{l}\text { EUP stent } \\
(\mathrm{n}=24)\end{array}$ & $\begin{array}{l}\text { DJ stent } \\
\text { ( } \mathrm{n}=38)\end{array}$ & $p$ value \\
\hline $\begin{array}{l}\text { Mean age } \pm S D, \text { months } \\
\text { Median age (range) }\end{array}$ & $\begin{array}{c}40 \pm 54 \\
11(2-195)\end{array}$ & $\begin{array}{c}80 \pm 78 \\
78.5(2-219)\end{array}$ & 0.03 \\
\hline $\begin{array}{l}\text { Sex, } \mathrm{n}(\%) \\
\text { Female } \\
\text { Male }\end{array}$ & $\begin{array}{l}8(33) \\
16(66)\end{array}$ & $\begin{array}{c}9(24) \\
29(76)\end{array}$ & 0.56 \\
\hline $\begin{array}{l}\text { Side, n (\%) } \\
\text { Left } \\
\text { Right }\end{array}$ & $\begin{array}{l}19(79) \\
5(21)\end{array}$ & $\begin{array}{l}23(61) \\
15(39)\end{array}$ & 0.17 \\
\hline $\begin{array}{l}\text { Reason for presentation, } \mathrm{n} \text { (\% } \\
\text { Antenatal hydronephrosis } \\
\text { Incidental diagnosis } \\
\text { Obstruction symptoms } \\
\text { Infection }\end{array}$ & $\begin{array}{c}19(79) \\
0(0) \\
3(13) \\
2(8)\end{array}$ & $\begin{array}{c}17(45) \\
7(18) \\
12(32) \\
1(3)\end{array}$ & 0.01 \\
\hline $\begin{array}{l}\text { Operative approach } \\
\text { Laparoscopic } \\
\text { Open } \\
\text { Laparoscopic converted to } \\
\text { open }\end{array}$ & $\begin{array}{c}7(29) \\
17(71) \\
0(0)\end{array}$ & $\begin{array}{c}21(55) \\
16(42) \\
1(3)\end{array}$ & 0.05 \\
\hline Mean follow-up \pm SD & $23.8 \pm 10.9$ & $21.1 \pm 11.1$ & 0.32 \\
\hline
\end{tabular}


Lee et al.

\begin{tabular}{|c|c|c|c|}
\hline & $\begin{array}{l}\text { EUP stent } \\
(\mathrm{n}=24)\end{array}$ & $\begin{array}{l}\text { DJ stent } \\
\text { (n= 38) }\end{array}$ & $p$ value \\
\hline Mean operative time $\pm S D$, minutes & $165 \pm 44$ & $188 \pm 68$ & 0.14 \\
\hline Laparoscopic & $211 \pm 25$ & $224 \pm 61$ & 0.32 \\
\hline Open & $147 \pm 35$ & $140 \pm 46$ & 0.59 \\
\hline Retrograde pyelogram, n (\%) & $11(46)$ & $9(24)$ & 0.10 \\
\hline Mean length of stay $\pm S D$, days & $1.3 \pm 0.6$ & $1.9 \pm 1.6$ & 0.07 \\
\hline Overall complications, n (\%) & $5(20.8)$ & $2(5.2)$ & 0.10 \\
\hline \multicolumn{4}{|l|}{ By timing } \\
\hline Intraoperative, n (\%) & $0(0)$ & $0(0.0)$ & - \\
\hline Less than 3 months, n (\%) & $3(12.5)$ & $1(2.6)$ & 0.29 \\
\hline Greater than 3 months, n (\%) & $2(8)$ & $1(2.6)$ & 0.55 \\
\hline \multicolumn{4}{|l|}{ By Clavien-Dindo Classification } \\
\hline i & $1(4.2)$ & $1(2.6)$ & 1.00 \\
\hline II & $2(8.3)$ & $0(0)$ & 0.15 \\
\hline III & $2(8.3)$ & $1(2.7)$ & 0.55 \\
\hline IV & $0(0.0)$ & $0(0.0)$ & 1.00 \\
\hline V & $0(0.0)$ & $0(0.0)$ & 1.00 \\
\hline
\end{tabular}

re-stenosis requiring ureteral stent and dilatation, without the need for further intervention. In contrast, one patient in the DJ group with a Clavien III complication had re-stenosis requiring ureterocalicostomy. These complications were also multifactorial and may not have been attributed to the method of stenting alone. Although there is a trend towards more Clavien III complications in the EUP than in the DJ group, the invasiveness of repeat interventions must also be considered. The two patients who had Clavien III complications in the EUP had a relatively less invasive intervention (i.e., cystoscopy, ureteral dilation and stent insertion) than the patient in the DJ stent group (i.e., ureterocalicostomy).

\section{Discussion}

Our analyses comparing outcomes of both laparoscopic and open pyeloplasty using EUP versus DJ stents suggest that there are no statistically significant differences in operative time, length of stay, and complication rates between the DJ and EUP stent groups. We reported complications employing the Clavien-Dindo classification system, also uncovering a lack of statistical significance and a low, acceptable com- plication profile. To our knowledge, this is one of the first studies to report this classification scheme in both open and laparoscopic pyeloplasties with EUP compared to DJ stents.

A recent large study reported on 238 patients who underwent open pyeloplasty drained with preoperative nephrostomy tube, no stent, an externalized feeding tube brought through the renal pelvis and DJ stent with nephrostomy tube. ${ }^{10}$ All groups had a low rate of failure or complications. Another series of 14 patients undergoing trans-peritoneal laparoscopic pyeloplasty described trans-anastomotic stenting externalized through the renal pelvis. No urine leaks were seen in their patients after removal. ${ }^{12}$ Recently, a series of young children (ages 1-5 years) undergoing laparoscopic pyeloplasty compared outcomes of patients undergoing "stentless" pyeloplasty, pyeloplasty with DJ stent and EUP. The authors' interpretation of their data led them to conclude value in limiting use of a stent for children with unfavourable intra-operative findings (such as subjective appearance of the pelvis or ureter, malrotation, solitary kidney, presence of fibrosis).$^{15}$ However, an alternative analysis of their findings (which included a historical open series) would support use of EUP stent. Our findings compare favourably with these reports (Table 3 ).

Of the patients in the EUP group, all $(n=24)$ were able to avoid a second anesthetic required for stent removal. Nevertheless, $8 \%(n=2)$ required a second anesthetic due to re-stenosis, leading to a second procedure. This has implications when considering potential neurotoxicity of anesthe$\mathrm{sia}^{6,7}$ as well as for minimizing the use of limited operating room resources. If a DJ stent is still preferred, an alternative technique involves the use of a urethral dangler for removal. The disadvantage to this technique is that patients may develop lower urinary tract symptoms or urinary tract infections, ${ }^{16}$ the string may be inadvertently pulled too soon after surgery or can migrate into the urethra, and retrograde placement before pyeloplasty would increase operative time. A DJ stent can also be tied to a feeding tube ${ }^{17}$ and removed in a similar manner as a EUP stent. A cost comparison of DJ and EUP stents using the original technique of passing the EUP stent through the renal parenchyma ${ }^{4}$ favoured the EUP stent.

As a retrospective study, the study has potential biases, including surgeon preference and case selection. An exam-

\begin{tabular}{|c|c|c|c|c|}
\hline & Open approach (n) & Laparoscopic approach (n) & Median follow-up (months) & Overall complication rate \\
\hline Castagnetti et al. ${ }^{18}$ & 228 & - & Not reported & $13 \%$ \\
\hline Eassa et al. ${ }^{12}$ & - & 14 & Not reported & None \\
\hline Helmy et al. ${ }^{11}$ & - & 11 & $34(22-56)$ & None \\
\hline Kocvara et al. ${ }^{19}$ & 26 & 15 & $36(4-84)$ & $3.8 \%-13.3 \%$ \\
\hline Son et al. ${ }^{10}$ & 122 & - & Not reported & $3.2 \%$ \\
\hline Taveres et al. ${ }^{9}$ & - & 4 & Not reported & None \\
\hline
\end{tabular}


ination of patient demographics revealed that these two groups are somewhat heterogeneous, with differences in age, presentation pattern and likely, duration of UPJO. In addition, as the technique of externalization via the renal pelvis has only been recently introduced, it diminishes the bleeding risk associated with passing a stent through the parenchyma. Lastly, our study may be underpowered to detect differences between the two groups. Despite these limitations, there is value in our findings. The present series adds to the limited data and provides compelling evidence that EUP stenting through the renal pelvis is safe and feasible for both laparoscopic and open procedures. Our report also underscores the need for further studies with EUP stents for pyeloplasty drainage, including the robotic-assisted approach, which may benefit from cost containment.

\section{Conclusion}

Our data suggest that operative times, length of stay, and intraoperative, early and late complication rates of laparoscopic or open pyeloplasty may be similar in patients who have drainage with DJ versus EUP stents. The latter provides several benefits, including avoiding a secondary anesthetic.

Competing interests: The authors declare no competing financial or personal interests. Dr. Salle declares that he no longer has an affiliation with the manufacturer of the Salle stent. He previously received royalties, which were donated to the Research Institute. The contract has since expired and he no longer receives royalties.

This paper has been peer-reviewed.

\section{References}

1. Smith KE, Holmes N, Lieb Jl, et al. Stented versus nonstented pediatric pyeloplasty: A modern series and review of the literature. J Urol 2002;168:1127-30. http://dx.doi.org/10.1016/S0022$5347(05) 64607-1$

2. Kim J, Park S, Hwang $\mathrm{H}$, et al. Comparison of surgical outcomes between dismembered pyeloplasty with or without ureteral stenting in children with ureteropelvic junction obstruction. Korean J Urol 2012;53:564. http://dx.doi.org/10.4111/kiv.2012.53.8.564
3. Elmalik K, Chowdhury MM, Capps SNJ. Ureteric stents in pyeloplasty: A help or a hindrance? J Ped Urol 2008;4:275-9. http://dx.doi.org/10.1016/i.jpurol.2008.01.205

4. Braga LHP, Lorenzo AJ, Farhat WA, et al. Outcome analysis and cost comparison between externalized pyeloureteral and standard stents in 470 consecutive open pyeloplasties. J Urol 2008;180:1693-9. http://dx.doi.org/10.1016/i.juro.2008.05.084

5. Yiee JH, Baskin LS. Use of internal stent, external transanastomotic stent or no stent during pediatric pyeloplasty: A decision tree cost-effectiveness analysis. J Urol 2011;185:673-81. http://dx.doi. org/10.1016/i.juro.2010.09.118

6. Hays SR, Deshpande JK. Newly postulated neurodevelopmental risks of pediatric anesthesia: Theories that could rock our world. J Urol 2013;189:1222-8. http://dx.doi.org/10.1016/i.juro.2012.11.090

7. Sun LS, Li G, DiMaggio C, et al. Anesthesia and neurodevelopment in children: Time for an answer? Anesthesiology 2008:109:757-61. http://dx.doi.org/10.1097/ALN.0b013e31818a37fd

8. Ritchie E, Reisman EM, Zaontz MR, et al. Use of kidney internal splint/stent (KISS) catheter in urinary diversion after pyeloplasty. Urology 1993;42:55-8. http://dx.doi.org/10.1016/0090-4295(93)90340-G

9. Taveres A, Manaboriboon N, Lorenzo AJ, et al. Insertion of an internal-external nephroureteral stent during pediatric laparoscopic pyeloplasty: Description of the technique. Urology 2008;71:1199-202. http:// dx.doi.org/10.1016/i.urology.2007.11.124

10. Son $\mathrm{LT}$, Thang $\mathrm{LC}$, Hung $\mathrm{LT}$, et al. Transpelvic anastomotic stenting: A good option for diversion after pyeloplasty in children. J Ped Urol 201 1;7:363-6. http://dx.doi.org/10.1016/i.jpurol.2011.02.027

11. Helmy T, Blanc T, Paye-Jaouen A, et al. A. Preliminary experience with external ureteropelvic stent: Alternative to double-J stent in laparoscopic pyeloplasty in children. J Urol 2011;185:1065-70. http:// dx.doi.org/10.1016/i.juro.2010.10.056

12. Eassa W, Al Zahrani A, Jednak R, et al. A novel technique of stenting for laparoscopic pyeloplasty in children. J Ped Urol 2012;8:77-82. http://dx.doi.org/10.1016/i.jpurol.2010.10.010

13. Sprunger JK, Reese CT, Decter RM. Can standard open pediatric urological procedures be performed on an outpatient basis? J Urol 2001;166:1062-4. http://dx.doi.org/10.1016/S0022-5347(05)65921-6

14. Ruiz E, Soria R, Ormaechea $E$, et al. Simplified open approach to surgical treatment of ureteropelvic junction obstruction in young children and infants. J Urol 2011;185:2512-6. http://dx.doi.org/10.1016/i. juro.2011.01.012

15. Reismann $M$, von Kampen $M$, Laupichler $B$, et al. Fast-track surgery in infants and children. J Ped Surg 2007;42:234-8. htrp://dx.doi.org/10.1016/i.jpedsurg.2006.09.022

16. Mohamed $M$, Hollins $G$, Eissa $M$. Experience in performing pyelolithotomy and pyeloplasty in children on day-surgery basis. Urology 2004;64:1220-2. http://dx.doi.org/10.1016/i.urology.2004.08.065

17. Romao RLP, Farhat WA, Pippi Salle IL, et al. Early postoperative ultrasound after open pyeloplasty in children with prenatal hydronephrosis helps identify low risk of recurrent obstruction. J Urol 2012;188:234753. http://dx.doi.org/10.1016/i.juro.2012.08.036

18. Castagnetti $M$, Berrettini $A$, Cimador $M$, et al. Complications of trans-anastomotic externalised stents in open pyeloplasty: Influence of the method of placement, the duration of stenting and the associated bladder drainage. Pediatr Surg Int 2009;26:309-13. http://dx.doi.org/10.1007/s00383-009-2495-7

19. Kocvara R, Sedlacek J, Drlik $M$, et al. Unstented laparoscopic pyeloplasty in young children (1-5 years old): A comparison with a repair using double-J stent or transanastomotic externalized stent. J Pediatr Urol 2014;10:1153-9. http://dx.doi.org/10.1016/i.purol.2014.04.017

Correspondence: Dr. Armando J. Lorenzo, Division of Pediatric Urology, Department of Surgery, The Hospital for Sick Children, 555 University Ave., Toronto, ON M5G 1X8; armando.lorenzo@sickkids.ca 